\title{
Effectiveness of reconstruction with additional floors for buildings of different construction periods
}

\author{
Liliya Pakhomova ${ }^{1,{ }^{*}}$, Boris Zhadanovskii ${ }^{1}$, Alexandra Chernyshov $^{1}$, Alina Iumasheva ${ }^{1}$, \\ and Elena Pankova ${ }^{1}$ \\ ${ }^{1}$ Moscow State University of Civil Engineering, 129337, 26, Yaroslavskoye Shosse, Moscow Russia
}

\begin{abstract}
There is a renovation program in Russia. It aimed to eliminate obsolete housing stock by the demolition of buildings, but there is an alternative - reconstruction with additional floors. Depending on the building construction period (1930-1955 or 1956-1968), the reconstruction technology differs in whether the load of new floors is transferred to old structures or to the new ones. This is determined by the condition and quality of the vertical supporting structures. The economic effect of construction will be different as a result of the various technologies application. It is also influenced by many factors such as limited sizes of construction site. This characteristic has a particularly large impact on the cost amount. The indicators of implemented projects of different construction periods are compared to determine the most advantageous reconstruction option. On the basis of the received information, it was established that the reconstruction with additional floors for houses built in 1930-1955 is more profitable than for houses built in 1956-1968. The last ones allow not only increasing the number of floors but also the expansion of apartments' area due to foundation changes and improvements. This requires the development of a solution to achieve the most efficient working methods.
\end{abstract}

\section{Introduction}

First industrial generation residential buildings are in a state of physical and moral deterioration. That's why they need to be liquidated as part of the renovation program in Russia. Due to some conditions, there is an alternative to the obsolete housing stock demolition. It is a reconstruction with additional floors which allows the floor rezoning according to modern requirements. It also makes possible to increase the area of rooms in order to bring the operational characteristics in accordance with the standards increasing the residents comfort level [1]. The reconstruction uses the existing reserves of building structures load-bearing capacities. According to experts, there is a large number of houses in Moscow that meet the requirements necessary for making a decision to carry out reconstruction with a floors number increase: these should be buildings of certain series whose physical deterioration does not exceed $50 \%$. Some additional conditions make it impossible to carry out a reconstruction, for example, remoteness from the road, the impossibility of apartments rezone

*Corresponding author: aljurgaitis@gmail.com 
due to the constructive scheme, the presence of town planning restrictions that requires the un-violated artistic unity of the inner block space. The decision on the possibility and necessity of reconstruction can be made only after a technical survey, analysis of a design planning decision and a feasibility study report [2-3].

This technique has many advantages. More than 93 million tons of demolition waste is generated per year [4]. There is no need to recycle a large amount of demolition waste, that's why the estimated cost is reduced by $40 \%$ of the cost of a newly built same area house [5]. There is no harm to the environment. Furthermore instead of expensive connection to engineering networks it is only necessary to increase its capacity. Reconstruction can be carried out without the resettlement of residents, that's why it is economically beneficial. This solves the problem of the city not having the required number of new housing for resettlement [6]. Reconstruction can cost up to $30 \%$ cheaper than new construction.

The building construction period influences technology scheme of adding floors. The final price per square meter of housing in these schemes will be different. So there is a question about which houses reconstruction is the most profitable and promising.

\section{Materials and Methods}

The houses of the first considered time period are from the end of the 1930s to the mid1950s. It is a part of time when USSR was under the rule of I.V. Stalin. The house-building task of that period was the qualitative improvement of living conditions. The houses are built of brick according to individual or serial project: SM-6, II-02, II-04, II-08, etc. These are buildings with a varied layout, spacious rooms and high ceilings (up to 4 meters); for many buildings it was projected individual facade solutions by using a large amount of decorations. Such kind of houses is characterized by high quality performance due to the construction technology careful observance. Low thermal conductivity and high sound insulation are based on the large thickness of the walls which is more than a meter. This brick walls have an excessive safety margin. The load-bearing capacity of such structures has not been exhausted up to nowadays, so this ultra-reliable brickwork allows adding floors by transferring the new floors load completely directly to the old structures. The house acquires a new area only by increasing its height in case of this method.

The houses of this period were erected as the first capital category buildings. The service life for the considered houses of the pre-war period is 125 years with a standard demolition time by 2050-2070, and the post-war period is 150 years with a standard demolition time by 2095-2105. According to research results the demolition of such buildings is a very expensive deal. It is advisable to carry out only for urban planning needs [7,8]. There are about 4300 of such houses in Moscow.

The decision on the adding floors is made by urban planning reasons, requirements for the building floors number, population density and insolation requirements [9].

Such a reconstruction scheme was applied to the building at Gazetny Lane 13b1, Moscow (Fig.1). The project was successfully implemented by a professional team of "Concern "Lusine" organization. Before the reconstruction it was a two-section residential brick house built in 1956 with 11 floors and 110 apartments, the amount of living area was 5699 $\mathrm{m}^{2}$. As the result of reconstruction 2 floors and a mansard were added to the building. Mansard reduces heat loss through the roof and attic by $7-9 \%$. It has been established that each mansard floor construction saves an average of 0.15 ha of the urban area [10]. At the same time, the cost of one square meter of space in the mansard floor is $30-50 \%$ cheaper compared to the cost of one square meter of space for newly built construction [11]. 


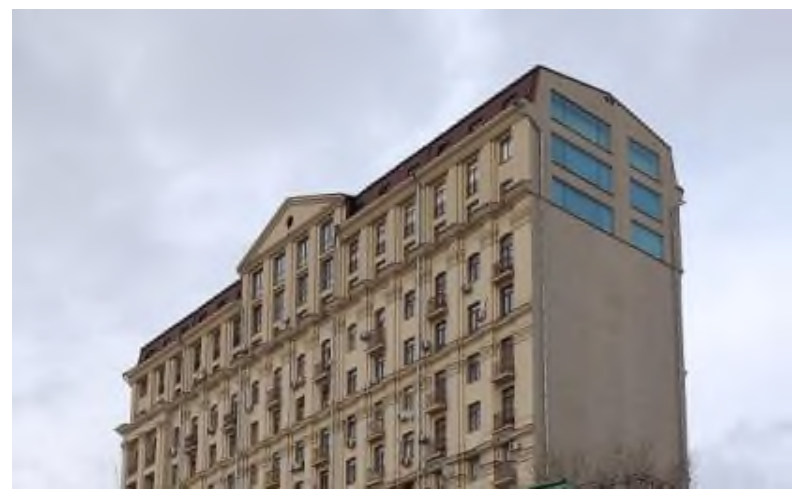

Fig. 1. Residential building of the period 1930-1955 after reconstruction.

The construction of the two additional floors and the mansard was carried out in such a way that all the supporting structures and vertical communications (stairs, elevators, risers and ventilation shafts) coincided with the existing ones. As a result of the reconstruction, 16 new apartments of a higher comfort level appeared and the living area became $9016 \mathrm{~m}^{2}$. Work on the additional floors was made without the resettlement of residents.

The second considered period is 1956-1968 when USSR was under N.S. Khrushchev rule. The law "On elimination of excesses in design and construction" adopted. After that, houses usually appear up to 5 floors high, with facades devoid of expressiveness, built of brick, blocks or panels according to standard designs which suppose small kitchens, small combined bathrooms, low sound insulation and incorrect heat and humidity conditions. These houses are represented by series 1MG-300, 1605-AM, II-35, II-32, K-7, etc. Those extremely low, almost incomplete space-planning and design solutions of such residential buildings meet only the minimum requirements. At present, their operation becomes impossible due to physical and moral wear. That's why there is an urgent need for renovation in order to improve the quality of development and increase the amount of existing buildings living space.

The considered houses were built to quickly solve the acute problem of providing the entire population with housing, therefore special demolished series were developed that were intended for a temporary solution to the housing problem - it was designed for 25 years, but some of them are still used for its intended purpose. The buildings of the nondemolished series had a calculated resource of 50 years, later studies showed that the resource could be extended to 150 years.

The low load-bearing capacity of vertical supporting structures is a determining factor on choosing a method to construct additional floors. The technology used in this example requires a new foundation created around the existing one. On this new foundation, monolithic external walls are erected with the aim of transferring to new walls the existing load from both the existing and the additional floors. After reconstruction, this building not only increased in height, but also received an additional area in width. Such space-planning decision is the most effective in terms of the total area yield during reconstruction as compared to conventional adding floors [12]. According to this technology, a five-storey residential building located at Khimki Boulevard 4, Moscow (Fig.2) avoided demolition and received four additional floors (Fig.3). As a result, living space increased 2.2 times from $4460 \mathrm{~m}^{2}$ to $9636 \mathrm{~m}^{2}$ (Fig.4). The basis is a panel house of a standard series 1-511 built in 1965. About 5.06 million $\mathrm{km}^{2}$ of living space in Moscow is occupied by this series of houses. Besides the fact that this technology was used in several houses reconstruction in Moscow, this is an indicative experience of this technology effective use because of additional floors large number. 


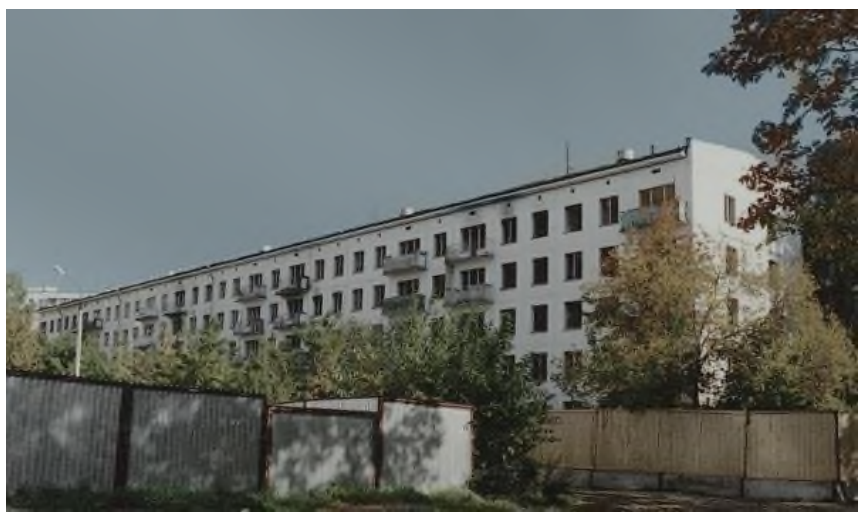

Fig. 2. First industrial generation residential building of the period 1956-1968 before reconstruction.

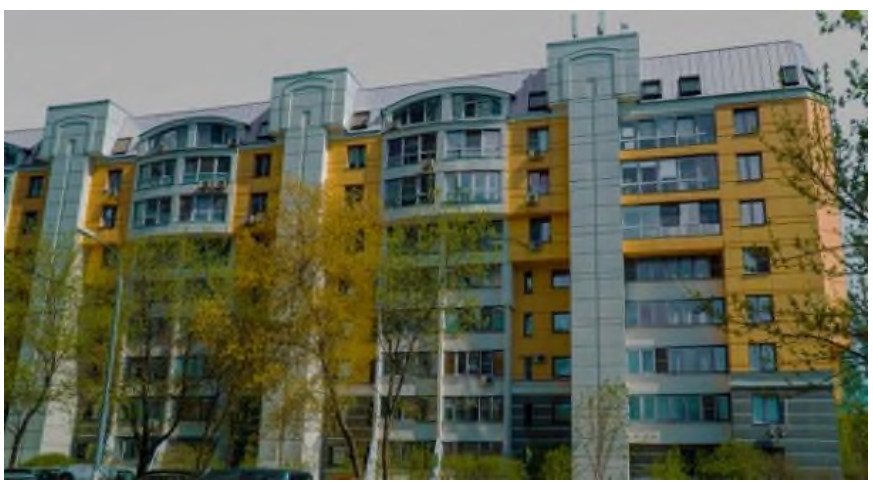

Fig. 3. First industrial generation residential building of the period 1956-1968 after reconstruction.

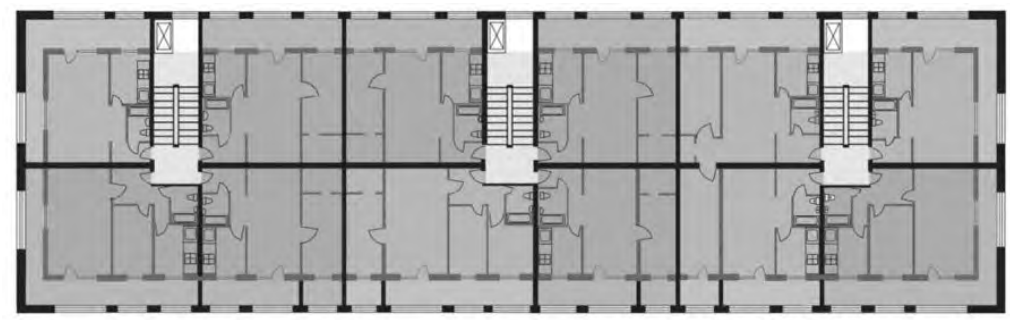

Fig. 4. Living space increase by expanding the building.

The reconstruction took place without the resettlement of residents and turned out to be at $10-15 \%$ lower cost than the cost of newly built construction.

In the process of reconstruction, a ventilated facade mounted system was installed, which added to the building area a previously absent architectural and artistic expression. The quality of life of people has improved not only due to the improvement of the technical and operational characteristics of enclosing structures, but also as a result of imparting architectural dynamism to a typical development object [13].

\section{Results}

The results of the reconstruction effectiveness evaluation in each considered case are summarized in Table 1. All data are given according to expert estimates. 
Table 1. The reconstruction relative profit calculation.

\begin{tabular}{|c|c|c|}
\hline \multirow{2}{*}{ Indicator } & \multicolumn{2}{|c|}{ Period of a residential house construction } \\
\hline & 1930-1955 & 1956-1968 \\
\hline $\begin{array}{c}\text { The estimated cost of reconstruction, } \\
\text { USD }\end{array}$ & 11200000 & 5800000 \\
\hline Increase in living space, $\mathrm{m}^{2}$ & 3317 & 5176 \\
\hline $\begin{array}{l}\text { The average price per } 1 \mathrm{~m}_{2} \text { of the addi- } \\
\text { tional area, USD }\end{array}$ & 3376.55 & 1120.55 \\
\hline $\begin{array}{l}\text { Average market price per } 1 \mathrm{~m}^{2} \text { of addi- } \\
\text { tional space after reconstruction, USD }\end{array}$ & 12100 & 2815.85 \\
\hline $\begin{array}{c}\text { The value of the average price per } 1 \mathrm{~m}^{2} \\
\text { of an additional area relative to the } \\
\text { average price per } 1 \mathrm{~m}^{2} \text { of the old exist- } \\
\text { ing area, } \%\end{array}$ & 358.35 & 251.29 \\
\hline
\end{tabular}

The high cost of reconstruction is a consequence of the fact that the technology of works without resettlement of residents is complex, time consuming and requires increased security measures. Reconstruction is carried out in several stages, totally taking about two years. As a percentage, registration of land and property relations lasts $12 \%$ of the time, the release of initial-permissive documentation -25 , design $-15 \%$, construction work $-40 \%$, commissioning of the object $-8 \%$.

In order not to disturb the peace of local residents, work should be carried out only at certain times of the day with a minimum amount of noise. The work schedule should be discussed with the residents. The building site is fenced, safe passages to the house are arranged for residents. Works are carried out in frame of very limited building site. It is necessary to provide space for construction equipment, temporary warehouses, domestic campus. Temporary engineering networks are laid. All decisions need to be described in the reconstruction organization project [14]. During the installation of the additional floor overlap the residents of the upper floors should be temporary relocated [15]. Any dynamic effects are excluded. Therefore the methods of work production are selected with the least impact on the daily lives of people. Thus, the complexity of the construction process organization and the applied technologies peculiarities negatively affect the cost of reconstruction.

It should be clarified that the increased price per $1 \mathrm{~m}^{2}$ of additional space after reconstruction of house built in 1930-1955 is based on not only the features of the construction process, but on its location and its rich history. Due to their historical and architectural value these houses are under state protection. Therefore, in order to preserve such objects, a specially increased price is set on them [16]. At the moment of its construction, these buildings were considered as elite housing. Construction was carried out in the city central areas with well-developed infrastructure in places overlooking the main attractions of the city and in close proximity to the main administrative institutions, in contrast to the houses built in 1956-1968 made for ordinary people throughout the city. Typical residents of the houses built in 1930-1955 are well-known academicians, musicians, generals, party ministers, so the houses were designed according to their needs. However, now these needs have changed and other living conditions have emerged that require the addition of floors.

Analyzing the information obtained, it can be concluded that the average price per $1 \mathrm{~m}^{2}$ of additional space relative to the average price per $1 \mathrm{~m}^{2}$ of earlier built area for houses built in 1930-1955 is more than for the houses built in 1956-1968. it is 1.43 times more profitable to carry out reconstruction with additional floors for buildings built in the first considered period (Table 1). 


\section{Discussion}

The data obtained indicates the reconstruction effectiveness of houses built in 1930-1955, but this does not mean that the houses built in 1956-1968 should not be reconstructed. More than $6 \%$ of the housing stock in Russia is made up of the model series houses built in 19561968. These residential buildings also need either demolition or reconstruction if it is possible. To increase the benefits of their reconstruction, it is necessary to minimize the estimated cost, laboriousness and duration of work while maintaining the high quality of performance. Finding the optimal solution is an important task that can be solved, for example, by technological solutions categorization.

\section{Conclusions}

Reconstruction with additional floors is almost 1.5 times more profitable to produce for houses built in 1930-1955 than for houses built in 1956-1968 (Table 1). Therefore, further research should be aimed at reducing the cost of reconstruction of first industrial generation houses built in 1956-1968 in order to create the most efficient production work. Construction companies need not to give preference to only one type of building, ignoring others that also need reconstruction in the same volume. As a result, reconstruction with additional floors can become a cost-effective alternative to demolition, while simultaneously solving the problem of obsolescence of the housing stock, the development of renovation, and the urban features of the city as a whole.

\section{References}

1. Y. Du, S. Wang, L.-zhe Jin, S. Wang, W.-mei. Gai, Experimental investigation and theoretical analysis of the human comfort prediction model in a confined living space. Applied Thermal Engineering, 141 (2018) https://doi.org/10.1016/j.applthermaleng.2018.05.057

2. P. Oleinik, A. Yurgaytis, Optimization of the annual construction program solution. MATEC Web of Conferences, 117, 00130 (2017), https://doi.org/10.1051/matecconf/201711700130

3. W. Bozejko, Z. Hejducki, M. Uchroński, M. Wodecki, Solving resourceconstrained construction scheduling problems with overlaps by metaheuristic. Journal of Civil Engineering and Management, 5(20) (2014). https://doi.org/10.3846/13923730.2014.906496

4. S. Oleynik, Amounts and sources of construction and demolition waste. Russian Journal of Resources, Conservation and Recycling, 3(1) (2016) http://dx.doi.org/10.15862/02RRO116

5. K. Grigorenko, O. Petreneva, Reconstruction of building of the first mass series as a way to increase the living space. Perm National Research Polytech. Uni. Bull.Construction and Architecture, 7(1) (2016) https://doi.org/ 10.15593/2224-9826/2016.1.06

6. L. Brooks, B. Lutz, From Today's City to Tomorrow's City: An Empirical Investigation of Urban Land Assembly. American Economic Journal: Economic Policy, 8(3) (2016). http://dx.doi.org/10.1257/pol.20130399 
7. D. La Rosa, M. Spyra, L. Inostroza: Indicators of Cultural Ecosystem Services for urban planning: A review. Ecological Indicators, 1(61) (2016). https://doi.org/10.1016/j.ecolind.2015.04.028

8. D. Topchiy, A. Shatrova, A. Yurgaytis, Integrated construction supervision as a tool to reduce the developer's risks when implementing new and redevelopment projects. MATEC Web of Conferences, 193, 05032, (2018) https://doi.org/10.1051/matecconf/201819305032

9. L. Glebushkina, L. Peretolchina, Residential development renewal: overbuilding or underbuilding. Systems. Methods. Technologies, 3(31) (2016) https://doi.org/10.18324/2077-5415-2016-3-182-191

10. A. Petrov, V. Peshkov, A. Petunin, Industrial technologies of reconstruction of large-panel buildings of the 1-335 series. MATEC Web Conf., 21204009 (2018) https://doi.org/10.1051/matecconf/201821204009

11. O. Petreneva, V. Pikuleva, Method of determining the economic efficiency of the city housing fund reconstruction. Proceedings of the Moscow State University of Civil Engineering, 3, 122-134 (2016) https://doi.org/ 10.22227/1997-0935.2016.3.122-134

12. Y. Kustikova, A. Matushkina, Techniques for reconstruction of the preserved housing stock. Proceedings of the Moscow State University of Civil Engineering, 10(109) (2017) https://doi.org/10.22227/1997-0935.2017.10.1090-1097

13. K. Borsi, T. Finney, P. Philippou, Architectural type and the discourse of urbanism. The Journal of Architecture, 7-8(23) (2018) https://doi.org/10.1080/13602365.2018.1513478

14. L. Pakhomova, S. Moiseeva, K. Tereshina, Air pollution by construction vehicles. IOP Conf. Series: Materials Science and Engineering, 463(4), 042041 (2018) doi:10.1088/1757-899X/463/4/042041

15. S. Sinenko, B. Zhadanovskiy, L. Pakhomova, Assessment of complex technological processes of concrete mixes preparation with on-site automated concrete mixing plants. IOP Conf. Series: Materials Science and Engineering, 463, 032032 (2018). doi:10.1088/1757-899X/463/3/032032

16. E. Diatchina, I. Ptuhina, Preservation of cultural heritage monuments. Construction of Unique Buildings and Structures, 4(55) (2017) https://doi.org/ 10.18720/CUBS.55.6 